\title{
LIMITES À LIBERDADE DE REUNIÃO E DA AUTONOMIA PRIVADA: FUNDAMENTOS NAS CONVENÇÕES INTERNACIONAIS DE DIREITOS HUMANOS
}

\author{
Keyla Cristina Farias dos Santos* \\ Mario Jorge Philocreon de Castro Lima**
}

RESUMO: A atual pandemia de covid-19 obriga muitos países como o Brasil a aplicar medidas restritivas que afetam liberdades individuais, como a liberdade de reunião e a autonomia privada, privilegiando a promoção do Direito à Saúde, também qualificado como direito fundamental. Essa política induz violação de normas internacionais de direitos humanos. No entanto, soluções compatíveis podem ser encontradas também nas próprias convenções internacionais de direitos humanos, pela utilização de cláusulas de exceção, pela demanda de deveres fundamentais, ou pela promoção de soluções jurídicas de proporcionalidade entre normas internacionais de mesmo valor.

Palavras-Chave: Liberdade de Reunião; Convenções Internacionais; Direitos Humanos

\section{LIMITS FOR FREEDOM OF ASSEMBLY AND PRIVATE AUTONOMY: FOUNDATIONS IN INTERNATIONAL HUMAN RIGHTS CONVENTIONS}

\begin{abstract}
The current covid-19 pandemic forces many countries like Brazil to apply restrictive measures that affect individual freedoms, such as freedom of assembly and private autonomy, privileging the promotion of the Right to Health, also qualified as a fundamental right. This policy induces violations of international human rights standards. However, compatible solutions can also be found in the international human rights conventions themselves, through the use of exception clauses, through the demand for fundamental duties, or through the promotion of proportionality legal solutions between international norms of the same value.
\end{abstract}

Key Words: Freedom of Assembly; International Conventions; Human Rights

\section{INTRODUÇÃO}

\footnotetext{
* Pós-doutora em Direito pela Universidade Federal da Bahia - UFBA. Doutora em Direito pela Universidade Federal de Minas Gerais-UFMG. Mestre em Gestão de Recursos Naturais e desenvolvimento local da Amazônia pelo Núcleo de Meio Ambiente da Universidade Federal do Pará - NUMA/UFPA. Bacharel em Direito pela Universidade Federal do Pará - UFPA. Parecerista e Conselheira Editorial na Revista Eletrônica do Conselho Nacional de Justiça - CNJ. Avaliadora científica do Congresso de Pós-graduação em Direito - CONPEDI. Advogada. Presidente e Coordenadora científica do Grupo de Estudos: New International Law. Professora de Direito Internacional Comparado na Universidade Federal do Pará. E-mail: keylafarias@ufpa.br. Orcid: http://0000-0003-3580-2217. CV: http://lattes.cnpq.br/4100519828334640.

**Doutor em Direito pela Universidade Federal de Pernambuco-UFPE. Mestre em Direito pela Universidade Federal da Bahia-UFBA. Mestre em Administração pela Universidade Federal da Bahia-UFBA. Procurador da Fazenda Nacional aposentado. Professor Associado da Faculdade de Direito da Universidade Federal da BahiaUFBA. malima@ufba.br; Orcid:http://0000-0001-9670-435X; CV:http://lattes.cnpq.br/2759364549381451.
} 
Na situação da atual pandemia da covid-19 as iniciativas dos governos federativos brasileiros em determinar restrições de condutas cotidianas e costumeiras às pessoas, ainda que temporárias, a exemplo de confinamentos, fechamento compulsório de estabelecimentos (lockdown), toque de recolher, ou uso obrigatório de máscaras têm causado reações de resistência de grupos prejudicados e mesmo investidas judiciais no intuito de cessação ou suspensão das regulamentações.

Em verdade, as medidas de restrição oferecem, de fato, notório impedimento ao exercício de liberdades individuais históricas, malgrado a excepcionalidade das circunstâncias impostas pela pandemia, que é transmitida em larga escala através dos sistemas respiratórios humanos, onde a velocidade de propagação induz efeitos devastadores e incontestáveis no sistema de saúde pública.

Por sua vez, as medidas de restrições que atingem as liberdades individuais estão fundamentadas no dever do Estado brasileiro de promover o Direito à Saúde, também qualificado como direito fundamental garantido à sociedade, sobretudo na sua expressão de componente do bem-estar coletivo.

As medidas de restrições regulamentares são sobretudo deflagradas pelos governos estaduais e municipais, na sua condição de poderes locais próximos às peculiaridades das inúmeras comunidades humanas nas quais se distribuem os centros urbanos brasileiros, mas induzem em cada uma delas a potencial violação das liberdades fundamentais.

A matéria de direitos fundamentais no ordenamento brasileiro contemporâneo se encontra orientada por convenções internacionais universais e regionais de direitos humanos, que estão habilitadas para oferecer subsídios para busca de uma solução de equilíbrio na garantia das liberdades individuais.

Nesse trabalho utilizamos os métodos descritivo e dedutivo para pesquisar nas convenções internacionais de direitos humanos alguns fundamentos disponíveis, com capacidade de auxiliar na produção dessa solução de equilíbrio.

\section{O FUNDAMENTO DA DIREITO DE REUNIÃO E A AUTONOMIA PRIVADA}

A liberdade de reunião se revela no mundo contemporâneo de matriz ocidental como um dos direitos fundamentais do homem e do cidadão enunciados no art. 20 da Declaração Universal de Direitos Humanos de 1948.

Esse direito ressaltado entre as liberdades individuais do ser humano pode ser encontrado naturalmente entre duas outras prerrogativas essenciais das pessoas, afirmadas nas 
declarações liberais pioneiras, sendo a primeira delas a liberdade de locomoção ou liberdade de ir e vir, consagrada sobretudo no Habeas Corpus Act de 1679, da qual a liberdade de reunião pode ser uma decorrência, e a segunda, a liberdade de associação, enunciada por expresso na declaração de direitos francesa de 1789 (art. $2^{\circ}$ ), da qual a liberdade de reunião pode funcionar como pressuposto.

Essas três liberdades são instaladas nas sociedades democráticas como faculdades de ação do indivíduo que operam em garantia de seu potencial de organização política, tal como vislumbrado pelos povos pioneiros nas lutas pela liberdade humana.

Nos documentos normativos de origem, a referência à liberdade do cidadão de reunirse com seus iguais se encontra melhor expressa na $1^{a}$ Emenda da Constituição dos EUA de 1791 (COMPARATO,1999, p.105), portanto componente dos direitos humanos de $1^{\text {a }}$ geração, isto é, aqueles que dizem respeito à proteção do indivíduo contra o estado, liberdade negativa garantida ao cidadão.

Em termos jurídicos, o fato da reunião pode ser verificado quanto a coisas ou quanto a pessoas, a reunião de pessoas consiste na agregação temporária de curta duração para realização de um objeto comum (DE PLÁCIDO E SILVA,1999, p.719).

As reuniões de pessoas podem ser públicas ou privadas, as primeiras são de livre participação e as últimas são reservadas a pessoas específicas voltadas para um interesse comum, além disso as reuniões podem ocorrer em locais fechados ou a céu aberto em praças ou vias públicas, quando então podem estar sob controle do poder de polícia em nome do sossego e da ordem pública (DE PLÁCIDO E SILVA,1999, p.719).

$\mathrm{Na}$ experiência da vida gregária entre humanos a faculdade de reunir-se com seus pares ocorre como conduta natural e espontânea dos indivíduos ou grupos de indivíduos, resultantes de diversas causas, e que não podem ser impedidas em condições normais, a exemplo da reunião de confraternização com familiares, com destaque para o culto religioso, assim como diligenciar atividades econômicas ou artísticas.

O próprio fenômeno de surgimento da civilização se desenvolve justamente pelo impulso de formação de cidades, núcleo central de referência de uma coletividade que se torna agregada de modo permanente em região determinada, para melhor garantir sua sobrevivência. Surge então a necessidade intermitente de diligenciar a sobrevivência e o bemestar da comunidade, embrião da reunião política. 
A reunião que interessa nesse trabalho é a reunião política, isto é, a reunião pública na qual os cidadãos iguais, convocados, convidados ou que de modo espontâneo se aglomeram para discutir e se manifestar sobre os destinos da coletividade, como registra a memória da quase mitológica Ágora de Atenas.

Nos textos políticos clássicos pode se verificar o direito de reunião como o primeiro momento político da Nação, como registrado no trecho: (SIEYÈS,1997,p.92)

"Mas, como há necessidade de clareza, e isso não é possível se se discorre em princípios, vamos pedir ao leitor que considere, pelo menos, na formação das sociedades políticas, três épocas cuja distinção nos prepara para os esclarecimentos necessários.

Na primeira concebe-se um número mais ou menos considerável de indivíduos isolados que querem reunir-se. Só por isso já formam uma nação; têm todos os direitos de uma nação, basta exercê-los. Esta primeira época caracteriza-se pelo jogo das vontades individuais. Sua obra é a associação. Elas são a origem do poder."

A reunião se diferencia da associação, que consiste em passo mais avançado da ação política, e se caracteriza como organização permanente fundada em pacto de vontades dos aderentes (SILVA,2009, p.114), que passam a atuar em conjunto com mais consistência para alcançar seu objetivo.

Outrossim, a liberdade de reunião é um direito-meio, que viabiliza a liberdade de expressão e a liberdade de associação, permitindo a participação da sociedade civil na vida política e social, pois a reunião em "local aberto ao público" é o instrumento que viabiliza essa participação social democrática (RAMOS,2020,p.788), imprescindível para a superação da crise sanitária global em que a humanidade está inserida na atualidade.

Celso de Mello, em um interessante julgado entendeu como inadequada, desnecessária e desproporcional a proibição pelo Decreto Distrital n 20.098/99, de manifestações públicas que utilizem carros, aparelhos e objetos sonoros na Praça dos Três Poderes, Esplanada dos Ministérios, Praça do Buriti e vias adjacentes, descreveu: “a liberdade de reunião traduz meio vocacionado ao exercício do direito à livre expressão das idéias, configurando, por isso mesmo, um precioso instrumento de concretização da liberdade de manifestação de pensamento, nela incluído o insuprimível direito de protestar" (ADI 1969, j.28.06.2007, Plenário DJ 31.08.2007) (LENZA,2020, p.1246).

As liberdades de locomoção, de expressão, de reunião e de associação, portanto, compõem o feixe de prerrogativas que informam a consciência do indivíduo de sua autonomia dentro de uma sociedade, e lhe garante dignidade como pessoa humana. Essa autonomia é 
experimentada pelo indivíduo no meio social de duas maneiras, a autonomia pública e autonomia privada.

A autonomia pública do indivíduo na sociedade significa sua prerrogativa de participar da vida coletiva na determinação dos rumos e bem-estar da comunidade, que consiste em característica da democracia (SARMENTO,2016, p.140).

A liberdade de reunião se apresenta como expressão da autonomia pública, e no seu exercício os cidadãos podem promover reuniões públicas ou privadas, sejam festivas ou por outros motivos como cultos religiosos, seja em locais fechados ou a céu aberto, como vem ocorrendo de modo desafiador em vários países do mundo.

A autonomia privada significa faculdade de autodeterminação do indivíduo para realizar as escolhas que lhe pareçam adequadas para sua vida pessoal (SARMENTO, 2016, p.140), e que também são resguardadas às pessoas como direito fundamental, como consta no art. 12 da Declaração Universal dos Direitos Humanos - DUDH, de 1948, e a exemplo da própria liberdade de ir e vir e do direito de propriedade, enunciados desde as declarações pioneiras.

A autonomia privada como expressão de liberdade do indivíduo autoriza que as pessoas, por exemplo, escolham seu modo de vestir e se compor diante das circunstâncias sociais, inclusive quanto à recusa de uso de máscaras de respiração em locais públicos.

Observe-se, porém, que restrições a liberdades de uso privado em locais públicos são comuns na vida social, a exemplo dos regulamentos de vestuários em tribunais e delegacias, o controle de porte de objetos na entrada de aviões, bem como regras de higiene em hospitais.

Em tempos recentes essas restrições têm aumentado, como acontece com a proibição de uso de produtos de tabaco, outrora restrita a ambientes coletivos privados como bares e restaurantes, mas que se estende para vias e praças públicas em alguns países, como norma necessária para proteger a saúde dos humanos em ambientes coletivos, e que afronta justamente a autonomia privada de uso de substância legal.

\section{A LIBERDADE DE REUNIÃO NAS CONSTITUIÇÕES BRASILEIRAS}

A liberdade de reunião consiste em direito fundamental tradicionalmente integrante das constituições brasileiras, constando presente desde os primeiros textos, elaborados não exatamente em ambiente democrático.

A primeira constituição brasileira do império de 1824 foi elaborada em sintonia com a influência européia da época (SILVA,1999, p.76), e incluía capitulação de direitos civis e 
políticos dos cidadãos brasileiros (Título V), mas, não havia menção à liberdade de reunião. A única sugestão nessa direção pode ser entrevista na possibilidade de culto a outras religiões, diversas da católica, desde que realizados em locais domésticos ou específicos que não se instituíam como templos, ou seja, ao modo de reuniões privadas em local não aberto.

A Constituição de 1891 foi promulgada por assembléia parlamentar, instituiu a república e pretendeu entregar ao povo sua liberdade não tutelada, nesse sentido manteve e ampliou uma Declaração de Direitos (Título IV, Seção II) que inseria a liberdade de reunião sem armas no art 72 , parágrafo $8^{\circ}$, no texto original. A intervenção da autoridade policial poderia ocorrer de modo excepcional para manter a ordem pública.

Em seguida, o regime republicano brasileiro de índole liberal sofreu o abalo da ruptura institucional da Revolução de 1930, e enfrentou a revolução constitucionalista de 1932 em São Paulo, mas evoluiu para promulgar por assembléia constituinte a Constituição de 1934, que iniciou a assumir um viés social nas diretrizes constitucionais brasileiras mas também uma ordenação mais autoritária, como se deduz do capítulo da segurança nacional (Título VI), com normas destinadas às instâncias militares. Essa constituição acompanha o culto do Estado forte inspirado no totalitarismo em ascensão na Europa (VILLA,2011, p.49) mas prossegue a tradição da declaração de direitos e garantias individuais que mantinha a liberdade de reunião sem armas (art. 113, item 11), mas com permissão de eventual intervenção da autoridade para assegurar a ordem pública, e podendo mesmo designar o local da reunião.

A Constituição de 1937 veio a ser elaborada sob a excepcionalidade do Estado Novo, como se verifica na sua promulgação pelos membros do Poder Executivo e não por parlamento eleito, mas contava com um capítulo de direitos e garantias individuais no qual constava a liberdade de reunião pacífica e sem armas, e em locais abertos, mediante declaração, que poderiam ser interditadas por razões de segurança pública. Essa constituição, como a anterior, também continha um capítulo de segurança nacional e um capítulo de defesa do estado, no qual estava previsto eventual estado de emergência, que poderia suspender a liberdade de reunião (art. 168, letra c). Além disso, tudo mudou depois da declaração do estado de guerra em agosto de 1942 por decreto do poder executivo, que revogou a liberdade de reunião e outros direitos, fundamentado na excepcionalidade da situação política.

A Constituição de 1946, promulgada por assembléia constituinte, restaura a normalidade democrática, que naturalmente estipula capitulação de direitos e garantias 
individuais e entre esses, a liberdade de reunião nos mesmos moldes que a constituição de 1934, isto é, reunião sem armas, onde a autoridade não pode impedir mas pode intervir somente para assegurar a ordem pública, e com faculdade de designar local.

Em seguida, instala-se no país o regime militar em 1964, em princípio para restaurar a ordem até as então previstas eleições de 1965, mas que permanece até 1985. Um momento relevante no decurso desse regime acontece na edição da Constituição de 1967, impelida ao Congresso por projeto elaborado pelo Executivo (VILLA,2011, p.96), e promulgada pelas mesas da Câmara e do Senado, para substituir a Constituição de 1946, e que reiterava os arbitrários AI $n^{\circ} 1$ a 4. Mais adiante seu texto foi revisto pela chamada EC nº 01/1969, por vezes referida como 'constituição de 1969', editada pelo tríplice comando militar que se sustentava no governo através do $\mathrm{AI} \mathrm{n}^{\circ} 5$, o qual proibia atividades ou manifestações políticas.

Curiosamente essas 'constituições' do regime militar continham capítulo de direitos e garantias individuais, certamente para manter as aparências, e nesses estava deferida a liberdade de reunião sem armas, com eventual intervenção da autoridade para manter a ordem pública, remetendo à lei ordinária a tarefa de definir necessidade de aviso prévio e designação de local. Esses dispositivos se tornaram úteis quando se reiniciou a mobilização política para restauração do poder civil na década de 80.

Por fim, a Constituição de 1988 ora vigente implementa a liberdade de reunião (art. 5º, XVI), dessa vez com mais plenitude, uma vez que a defere independente de autorização e em locais abertos ao público, cabendo somente aviso prévio e o cuidado de não frustrar outra reunião no mesmo local.

Portanto, verifica-se que a liberdade de reunião e outras liberdades individuais sempre estiveram presentes em todas as constituições brasileiras, e apenas foram reduzidas ou reprimidas em períodos de anormalidade política.

\section{DIREITO À SAÚDE NA CONSTITUIÇÃO DE 88 E CONVENÇõeS INTERNACIONAIS}

O Direito à Saúde se encontra relacionado em diversas convenções internacionais de direitos humanos tanto as universais como as regionais. Por sua vez, o Direito à Saúde manifesta faceta geminada porque, embora se materialize sobretudo sob a natureza de direito individual a ser desfrutado por cada pessoa, o direito à saúde também pode assumir dimensão mais ampla supraindividual, que lhe confere o caráter de bem coletivo (BIDART CAMPOS, 
p.64,2003), incluindo-se na composição da noção de meio ambiente sadio, e objeto de políticas e ações públicas de destinação coletiva.

Em qualquer das expressões do Direito à Saúde, seja como bem individual ou bem coletivo, o ator juridicamente obrigado a garanti-lo será o Estado em todas as circunstâncias, ainda que não seja o único (GARCIA,2013, p.269)

Na Constituição de 1988, o direito à saúde a ser desfrutado por todos consta no art. 196, que determina o dever do estado de garanti-lo através de políticas sociais e econômicas, mediante ações de saúde prestadas por operadores públicos ou privados, sob liderança e regulação do poder público, conforme art. 197, firmando-se como componente dos direitos fundamentais nos termos da extensão declarada no art. $5^{\circ} \S 2^{\circ}$.

Na principal convenção internacional de direitos humanos, a Declaração Universal de Direitos Humanos - DUDH de 1948, o Direito à Saúde está mencionado no art, 25, incluído como componente essencial do bem estar a que tem direito todas as pessoas. Em seguida, o Direito à Saúde está reiterado no art. 12 do PIDESC $^{1}$, protocolo complementar à DUDH, que se estende em recomendações de ações aos estados signatários para garantir sua efetivação.

Nas convenções regionais, o Direito à Saúde está enunciado no art. $11^{\circ}$ da Declaração Americana dos Direitos e Deveres do Homem - DADDH de 1948 e reforçado no art. 10 do Protocolo de San Salvador - PSS, também informado nessa convenção com recomendações instrutivas das políticas a serem desenvolvidas pelos estados-membros para efetivar a saúde como direito de seus cidadãos.

No entanto, observe-se que essas convenções traçam diretrizes de natureza apenas política aos estados e não implantam nenhum órgão internacional de regulação efetiva ou prestação de serviços de saúde.

A entidade internacional que existe com atribuições técnicas dirigidas para os membros da comunidade internacional é a OMS - Organização Mundial da Saúde criada em 1946 em decorrência do surgimento da ONU, e que representa o sucesso de esforços centenários da civilização ocidental, através de conferências sobre saúde e controle sanitário iniciadas no século 19.

A OMS elabora os compromissos normativos internacionais de natureza técnica mais importantes sobre a temática da saúde, de alcance multilateral, entre os quais o mais

\footnotetext{
${ }^{1}$ Protocolo Internacional sobre Direitos Econômicos, Sociais e Culturais da ONU
} 
importante e atual consiste no regulamento $\mathrm{IHR}^{2}$ - International Health Regulations de 2005, que estabelece os deveres de conduta dos participantes quando da emergência ou risco de surtos, epidemias ou pandemias de alcance internacional.

A versão atual do IHR foi elaborada em 2005 depois da crise da SARS-Cov-1 nos anos de 2002/2003. Suas disposições descrevem a noção de enfermidade ou doença e estabelece a definição de 'emergência de saúde pública de importância internacional' (art. $1^{\circ}$ ) que deve induzir uma resposta internacional coordenada (GARCIA,2013, p.281).

O IHR/2005 estabelece obrigações de três tipos para os estados-membros, quando da emergência de moléstia de potencial risco ou alcance internacional: - as medidas imediatas (hard-and-fast), que constam nos art. 05 a 14, a exemplo da obrigação de notificação da OMS em 24h quando da identificação do surgimento da emergência, - medidas de ação contínua (protacted), que constam nos art. 15 a 18, a exemplo da obrigação dos estados de criar e manter estruturas de saúde adequadas e capacitadas ao enfrentamento de surtos e epidemias, e as - medidas de contingência (contingent), que constam nos art. 43 a 46, que determinam a obrigação de informar as medidas diligenciadas pelos estados para enfrentamento de epidemias, que sejam mais completas que os procedimentos previstos pelo regulamento e que contenham base científica.

Por conseguinte, o regulamento IHR somente determina obrigações de notificação e de atuação aos países membros e não atribui poderes à OMS para impor responsabilidade aos estados por descumprimento de suas disposições.

Da mesma forma, o IHR não implanta e nem existe serviço de saúde internacional, ou seja, administrado por organismos internacionais. Os serviços existentes com essa amplitude são mantidos por entidades privadas humanitárias, ainda que de alcance internacional, como a Cruz Vermelha e a Médicos sem Fronteiras, e não são suficientes nem possuem autonomia para conter epidemias internacionais.

Portanto, cabe de qualquer modo aos serviços de saúde dos estados nacionais nos seus territórios e em cooperação intergovernamental coordenada, inclusive com atores não estatais, o enfrentamento direto das crises de saúde regionais ou internacionais.

No caso específico do Brasil, na atual crise da pandemia do covid-19 subsiste ainda a dificuldade da extensão territorial e as diferenças regionais, que determinam a atuação dos poderes locais nas regulações e ações de enfrentamento da crise. Em razão dessas dificuldades

\footnotetext{
${ }^{2}$ RSI - Regulamento Sanitário Internacional 2005, aprovado pelo Dec. Legislativo no 395/2009
} 
adicionais, agravadas pelo destempero de conflitos políticos vexatórios, que obrigaram até uma decisão judicial do $\mathrm{STF}^{3}$, a tarefa veio a ser distribuída também aos governos estaduais e municipais, orientada pela lei federal $n^{\circ} 13.979 / 2020$, que veio a ser reproduzida com algumas variações regionais na classificação de atividades essenciais, restrições e sanções aplicáveis (VENTURA, DUARTE, 2021, p.34).

Essa distribuição de atribuições aos poderes regionais encontra respaldo também na Convenção Americana de Direitos Humanos - CADH, art. 28, cláusula federal, que determina aos estados signatários constituídos como federação, que determinem às entidades internas de governo, conforme seu ordenamento nacional, que implementem as medidas necessárias ao cumprimento da convenção.

Registre-se também que o conceito de seguridade humana assume sentido mais amplo desde os anos 90, para incluir também o conceito de seguridade sanitária, que pode ser entendido como a necessária proteção contra riscos e ameaças à saúde pública, que são de amplo espectro e não respeitam fronteiras (GARCIA,2013, p.278).

Vale lembrar que o controle de fronteiras e políticas migratórias restritivas costumam ser instrumentalizadas em ações estatais de controle de pandemias, mas são diligências desaconselhadas pela OMS, sobretudo porque fomentam a migração ilegal e com isso reduzem a eficiência dos controles epidemiológicos (BARROS,2015, p.94). Essas medidas somente se justificam na dependência do tipo de contaminação que dissemina a moléstia.

Desse modo, resta esclarecido o status do Direito à Saúde como componente inarredável dos direitos humanos nos termos das convenções internacionais e como direito fundamental positivado na constituição brasileira.

Por sua vez, resta fortalecida a prerrogativa dos estados nacionais de diligenciar a proteção de suas populações em nome de segurança sanitária social.

\section{A HABILITAÇÃO DO ESTADO PARA LIMITAR LIBERDADES INDIVIDUAIS NAS CONVENÇÕES INTERNACIONAIS DE DIREITOS HUMANOS}

Os movimentos afirmativos das liberdades individuais surgiram primeiro na Inglaterra medieval, e atuaram em resistência aos arbítrios e tiranias de autoridades, justificadas no poder absoluto com o qual se investia o Estado na sua concepção original. Mais tarde, essas reivindicações eclodiram de forma violenta na França e no atual Estados Unidos da América,

\footnotetext{
${ }^{3}$ ADI 6341
} 
pelas mesmas razões, e neste último aproveitado para justificar também a pretensão de independência.

No entanto, essa memória está reservada ao passado, porque o desfecho da luta de resgate pelos cidadãos de sua própria liberdade, ao final, resultou no ajuste de limites da atuação do Estado sobre a sociedade, que permanece incumbido de organizá-la.

Em termos contemporâneos, o Estado consiste na estrutura encarregada de regular a concorrência entre poderes múltiplos dos quais se constitui o universo político, que existe como uma ordem em movimento e funciona mediante equilíbrio de forças (BURDEAU,2005, p.97), que, eventualmente deixadas aos seus impulsos, findariam por se destruir mutuamente ou haveria predomínio de uma das forças políticas, que então se tornaria tirânica e extintiva das liberdades coletivas.

Portanto, cabe ao Estado manter o equilíbrio social, e para cumprir essa tarefa, sua estrutura recebe poderes delegados da sociedade para regê-la, para governá-la, que não desbordam em razão da harmonia tripartite dos poderes políticos e sob vigilância ativa da sociedade civil. Entre os poderes delegados ao Estado constam o poder regulatório e o poder de polícia, operados para determinar restrições e repressões a atividades perturbadoras do bem comum e impedir que o exercício de direitos de um indivíduo resulte em lesão aos direitos ou liberdade dos demais indivíduos.

A busca do equilíbrio social consiste na tarefa de harmonização dos interesses dos membros individuais ou de grupos desses indivíduos ou de toda a comunidade, que podem ser qualificados respectivamente como interesses individuais, interesses coletivos, e interesses gerais ou interesse público, onde o interesse coletivo consiste em somatório de interesse individuais, e o interesse público consiste em somatório de interesses individuais e coletivos (GUERRA FILHO, p.244,2003), de modo que o atendimento ao interesse público significa atender intrinsecamente aos interesses individuais e coletivos.

Observe-se que a atuação do Estado no exercício de sua governança não raro causa afetação aos direitos fundamentais das pessoas, ainda que produzida na sua instância mais definitiva, o poder judiciário. Contudo essa eventual limitação ao desfrute de direitos não é desconhecida nem inesperada na dinâmica sócio-política.

A noção de limite ao exercício de direitos humanos está reconhecida desde a declaração de direitos do homem e do cidadão de 1789, que no art, 4 descreve a liberdade, em linhas gerais, como o poder de fazer tudo que não prejudique a outrem, e que o limite ao 
exercício de direitos ocorre quando esse exercício oferece impedimento ao exercício de direitos pelos demais membros da comunidade. A mesma declaração estabelece limite à liberdade de opinião, art 10, estipulando que essa manifestação não deve perturbar a ordem pública (COMPARATO,1999, p.139).

O dever de pagar impostos, por exemplo, consiste em limite ao exercício pleno do direito fundamental de propriedade, como se verifica também na declaração de direitos do homem e do cidadão de 1789, art, 13 e 17, que contrapõe ao direito de propriedade o dever de contribuição para as despesas de administração e de necessidade pública.

Nessa matéria, observa-se que o dever de pagar impostos compõe a própria noção contemporânea de cidadania (TORRES,2001, p.318) inserida na sociedade democrática ordenada pelo estado de direito liberal.

$\mathrm{Na}$ situação da atual pandemia da covid-19, as ações dos governos, por suas características, operam notórias limitações às liberdades individuais, porém encontram fundamento justamente na possibilidade de restrições a direitos fundamentais (ALEXY,2008, p.276), e por conseguinte, as determinações de limitar a autonomia pública do indivíduo, com repressão da sua liberdade de reunião, ou intervir na sua autonomia privada ao determinar uso de máscaras e práticas de higiene pessoal em locais públicos, podem ser admitidas com respaldo na possibilidade jurídica de se estabelecer limites ao exercício de liberdades individuais.

Da mesma forma, as ações restritivas temporárias dos governos podem se justificar também em direitos vislumbrados para o proveito coletivo, os direitos de prestação em sentido amplo, a exemplo do direito de proteção e do direito de organização e procedimento, que são direitos a obter ações positivas incumbidas ao Estado para garantir o desfrute dos direitos fundamentais pela comunidade (ALEXY,2008, p.442).

As normas internacionais de direitos humanos se constituem em mandamento de atuação aos estados em favor de seus cidadãos, a serem aplicadas de modo efetivo em seus territórios. Portanto, são normas de eficácia imediata que demandam dos aparelhos estatais a garantia de realização mediante ações positivas, seja por políticas públicas promocionais, seja por atuação do poder regulamentar, ou seja pelo poder julgador diante dos eventuais impasses que surjam da omissão de sua aplicação ou aplicação desvirtuada, com efeitos indesejáveis sobre outros direitos e preceitos. 
Em adendo, cabe recordar a atribuição de Deveres aos Estados estipulados nos art. $1^{\mathrm{o}} \mathrm{e}$ $2^{\circ}$ da Convenção Americana de Direitos Humanos - $\mathrm{CADH}$, que informa seus signatários da sua obrigação de respeitar os direitos estabelecidos naquela convenção, e garantir seu exercício, bem como a obrigação de elaborar disposições de direito interno compatíveis com a efetivação dos direitos ali estabelecidos.

Nesse sentido, o fundamento para a imposição pelos estados de ações restritivas de liberdades individuais no período da atual pandemia, que já perdura por mais de um ano, pode ser encontrado nas convenções internacionais de direitos humanos, e pode se valer de três instrumentos jurídicos: as cláusulas de exceção de convenções internacionais de direitos humanos; os deveres fundamentais previstos em convenções internacionais de direitos humanos; e o método de ponderação aplicável nas colisões de direitos fundamentais

\subsection{Cláusulas de Exceção em Convenções Internacionais de Direitos Humanos}

No âmbito do direito internacional, a primeira possibilidade de fundamento para os estados em estabelecer suspensão ou restrições temporárias de liberdades individuais em seu território pode ser encontrada nas cláusulas de exceção.

Essas cláusulas estão estipuladas em algumas convenções de direitos humanos para aplicação somente em situações anormais, de exceção, com potencial de ameaça à própria existência da nação.

A situação anormal pode ser entendida como aquela decorrente de acontecimentos perturbadores ou impeditivos da maior parte das atividades habituais ou costumeiras da população do Estado, com efeitos deletérios sobretudo para o desempenho econômico e a organização da vida social.

A situação anormal, geralmente denominada como crise, se caracteriza como excepcionalidade justamente por causar uma descontinuidade duradoura ou definitiva no destino imediato ou mediato daquela nação.

As crises ou situações excepcionais podem surgir de incidentes de fato, a exemplo das catástrofes naturais, ou acidentes artificiais de grande alcance como os nucleares e contaminação química, ou mesmo causadas por atores humanos como são as crises econômicas e as políticas, essas últimas com potencial de instalar conflitos armados de escala ilimitada. 
Vale registrar que os fatos naturais ou acidentes artificiais, em regra, provocam crise ou situação excepcional de modo súbito, enquanto que as crises decorrentes de atores humanos se instalam progressivamente ao longo de movimentos das forças sociais.

Nas convenções de direitos humanos as cláusulas de exceção existem sob duas modalidades, as cláusulas derrogatórias, que suspendem temporariamente e sob certas condições o desfrute de alguns dos direitos humanos que estão enunciados no seu conteúdo normativo, e as cláusulas restritivas, que apenas autorizam limitações ao desfrute dos direitos que a convenção declara (PÉREZ,2013, p. 9).

Exemplo de cláusula derrogatória em tratado universal de direitos humanos pode ser encontrada no art. $4^{\mathrm{o}}$ do $\mathrm{PIDCP}^{4}$, que, em situações de exceção, capazes de significar risco para a existência da nação, autoriza a suspensão das obrigações dos Estados pactuadas nessa convenção.

Esse dispositivo também traceja os limites da aplicação dessa suspensão, ao vedar que a medida acarrete qualquer discriminação de raça, cor, sexo, língua, religião ou origem social, ou que a medida alcance alguns dos direitos de incolumidade física, de locomoção, de personalidade ou de crença das pessoas (art. $4^{\circ}$, item 2).

Registre-se que a liberdade de reunião, declarada no art. 21 dessa convenção, e a vedação de ingerência na vida privada (art. 17) não estão fora do alcance da eventual suspensão de desfrute.

Ademais, o art. $5^{\circ}$ do PIDCP interpõe outro limite à aplicação da cláusula de exceção, porque determina que a interpretação da mesma, para fins de aplicação, somente deve ocorrer dentro dos termos determinados na própria convenção.

No plano regional, a Convenção Americana de Direitos Humanos - CADH também apresenta cláusula de exceção derrogatória no art, 27, informada para situações de guerra, perigo público ou emergências, com disposições muito aproximadas ao conteúdo da cláusula do PIDCP, inclusive quanto ao alcance das medidas excepcionais.

Exemplo de cláusula de exceção restritiva em tratado universal de direitos humanos pode ser encontrada no art. $4^{\circ}$ do PIDESC, que permite regulações por lei do desfrute dos direitos dessa convenção, com o objetivo de favorecer o bem-estar geral da sociedade do Estado parte. Essa convenção também estipula limites à interpretação (Art $5^{\circ}$ ) da cláusula limitativa (GARCIA, 2013, p 274).

\footnotetext{
${ }^{4}$ Protocolo Internacional sobre Direitos Civis e Políticos da ONU
} 
Por sua vez a Convenção Americana de Direitos Humanos - CADH, no seu art 30, também admite regulações por lei para as restrições que autoriza ao longo de seu texto.

Vale registrar que as cláusulas derrogatórias são mencionadas nessas convenções como destinadas a um dos estados-parte, de modo individual, que esteja a enfrentar eventual situação de crise. Os demais estados-parte serão informados da situação de crise por meio da ONU no início e no final do período de exceção, com sua justificativa, subentendido que os demais estados-parte devem tolerar e assimilar a excepcionalidade.

Isso significa que essas cláusulas não foram previstas para utilização numa crise global como a atual pandemia da covid-19, que afeta todos os estados, mas efetivamente apresentam utilidade equiparada para todas as partes, cabendo a cada estado aplicar as exceções na medida de suas necessidades.

\subsection{Deveres Fundamentais em Convenções Internacionais de Direitos Humanos}

O segundo instrumento jurídico apto a fundamentar as restrições a liberdades individuais das pessoas se encontra nos Deveres Fundamentais, atribuídos por algumas convenções internacionais de direitos humanos, e admitidos em doutrina jurídica convicta de sua validade em diversos estudos passados e recentes de eruditos de ciências sociais.

As constituições brasileiras não revelam tradição de mencionar deveres fundamentais dos cidadãos de modo paritário com as declarações de direitos, embora os enuncie em temas específicos voltados para deveres patrióticos e cívicos, a exemplo do dever de defesa da pátria, presente desde a constituição a 1824, e deveres cívicos como o dever de pagar impostos e o dever de frequentar ao ensino primário gratuito, este incluído a partir da Constituição de 1934 (MARTINS,2011, p.52),

Na Constituição de 1988, os deveres fundamentais são mencionados no título do Capítulo I, do Título II, Dos Direitos e Deveres Individuais e Coletivos, mas não recebem declinação ordenada a exemplo dos direitos individuais, contudo, encontram-se deveres dessa qualidade distribuídos de modo pontual no texto constitucional, a exemplo do dever de alistamento eleitoral e do voto ( $\operatorname{art} .14 \S 1^{\circ}$, inciso I),

Os Deveres Fundamentais se revelam como sujeições passivas impostas pelo Estado aos indivíduos, necessárias à proteção dos Direitos Fundamentais (MARTINS, 2011, p.57), e tal como estes, podem ser entrevistos além da ordem constitucional formal.

Esses deveres estão presentes desde a declaração de direitos e deveres do homem e do cidadão de 1795 na França, e também constam no art, 29 da Declaração Universal de Direitos 
Humanos - DUDH de 1948. Deveres Fundamentais também estão estipulados nos art 29 a 38 da Declaração Americana dos Direitos e Deveres do Homem - DADDH de 1948, e no art. 32 Convenção Americana de Direitos Humanos - CADH, Pacto de San José de Costa Rica.

Os deveres estipulados nessas convenções são todos dirigidos às pessoas, seres humanos, no intuito de lhes atribuir consciência de suas obrigações de cooperação e colaboração de esforços para com o bem-estar comunidade na qual estão inseridos.

Essa consciência de deveres pode funcionar como estímulo ao ativismo cívico ou comunitário dos indivíduos (LIMA,2006, p.179), tornando-os parceiros do protagonismo do Estado na realização das aspirações sociais e como mais um instrumento para conferir efetividade aos direitos fundamentais.

Por sua vez, cabe registrar que os direitos sociais reconhecidos como direitos humanos são orientados pelo princípio da solidariedade (COMPARATO, 1999, p.52), e na sua efetivação reclamam a imputação de correspectivos deveres de solidariedade (TORRES,2001,p.321) atribuídos aos mesmos destinatários.

Por conseguinte, o implemento de medidas restritivas de liberdades individuais podem ser sustentadas de modo legítimo na demanda de cumprimento de obrigações cívicas e sociais pelas pessoas, orientadas pelos deveres fundamentais para com a comunidade da qual participam.

\subsection{A Ponderação aplicável na Colisão de Direitos Fundamentais}

$\mathrm{Na}$ abordagem do terceiro instrumento jurídico, cabe antes admitir que as circunstâncias técnicas e práticas com as quais se combate a disseminação da pandemia de covid-19 determinam restrições à liberdade de locomoção e de reunião das pessoas, bem como interferem em suas autonomias privadas com imposições de uso de máscaras e fechamento temporário de negócios, que são essenciais para a vida econômica e social e notoriamente lesivos aos interesses patrimoniais de famílias.

Por sua vez, essas restrições se justificam em apelo de predomínio necessário de um outro direito fundamental, o Direito à Saúde, no caso, observado segundo sua dimensão de bem coletivo.

A situação, portanto, revela conflito latente quanto à faculdade de desfrute ou postulação de dois tipos de direitos humanos, assim qualificados em normas constitucionais e internacionais, a ser enfrentado por juízo de proporcionalidade, de modo a garantir a subsistência harmônica dos valores e princípios imanentes contidos nos direitos em conflito. 
Nas circunstâncias de casos concretos onde surgem a tensão de conflito ou colisão entre princípios, a decisão a realizar sempre significará privilégio de um dos princípios em detrimento de outro, embora todos se mantenham íntegros na sua validade, porém reduzidos na sua eficácia, no âmbito específico do caso em análise (GUERRA FILHO, p.522,2006).

A base do argumento de princípios forma a distinção entre regras e princípios. Regras são normas que ordenam, proíbem ou permitem algo definitivamente ou autorizam a algo definitivamente.

Elas contêm um dever definitivo. Quando os seus pressupostos estão cumpridos, produz a consequência jurídica. Caso não queira aceitar esta deve-se declarar a regra como inválida e com isso despedi-la do ordenamento jurídico, ou então, inserir-se uma exceção na regra e nesse sentido, criar uma nova regra. Salientando que, a forma de aplicação da regra é a subsunção.

Por outro lado, os princípios contêm um dever ideal, sendo mandamentos a serem otimizados, assim sendo não contém um dever definitivo, mas um dever prima-facie. Sendo assim considerados "mandamentos de otimização" sendo importante sua ponderação enquanto dever primário que deve zelar pelo dever real e definitivo no ordenamento jurídico (ALEXY,1999, p.74).

Nesse sentido, a argumentação fundamentada na teoria dos princípios se revela mais promissora para solucionar com equilíbrio os casos concretos de conflito jurídico entre o exercício pleno de direitos fundamentais, que devem ser qualificados como colisões de princípios (ALEXY,1999, p.75).

O efeito indesejável do conflito entre princípios ocorre quando a aplicação dos direitos fundamentais em favor de um indivíduo ou grupo induz afetação de direitos fundamentais de terceiros específicos ou da coletividade.

Em algumas situações encontram-se a colisão de princípios em sentido estrito (ALEXY, 1999, p,71), que pode decorrer de colisões de direitos fundamentais iguais ou diferentes de indivíduos diferentes. Em outras situações surge a colisão entre direitos fundamentais em sentido amplo (ALEXY,1999, p.71), nas quais a aplicação de direitos fundamentais afeta bens coletivos, a exemplo da saúde ou segurança, que podem ser desfrutados não somente de modo individual como coletivo.

Observe-se que a saúde ou a segurança pessoal de um indivíduo pode ser afetada não somente por seu próprio comportamento, por exemplo, ao se oferecer a riscos, mas também 
pelo comportamento de outros, que com sua conduta temerária ou descuidada, induza perigo à saúde ou segurança individual ou coletiva de outros.

Essa parece ser a situação em que se encontram os países afetados pela pandemia, a exemplo do Brasil, quando enfrentam o impasse decisório de proibir e dispersar reuniões livres de cidadãos, inclusive em situações privadas e locais fechados, ou determinar fechamento de atividades e uso de máscaras, por causa do risco da contaminação viral.

Nesses casos, a aplicação das restrições que favorecem determinados direitos fundamentais ou bens coletivos não podem encontrar justificativa para seu predomínio por implemento de solução de validade ou não validade, porque não se trata conflito de normas tipo regras, mas conflito de normas tipo princípios.

A colisão entre os direitos fundamentais, privilegiados pelo alcance das restrições, contra as liberdades individuais eventualmente prejudicadas pelas mesmas imposições, reclama solução de equilíbrio com flexibilidade, na qual se busca harmonizar a concorrência de atuação entre todos os valores em jogo, através da reserva do possível (ALEXY,1999, p.79), delimitada em ponderação metódica.

O resultado da ponderação pretenderá determinar como os desfrutes parciais dos direitos fundamentais serão distribuídos aos postulantes, ao modo de como se desfruta das liberdades no meio social, isto é, liberdades limitadas pelo bem-estar geral, que somente ocorre quando a vivência da liberdade não lesar direitos de ninguém

Por sua vez, o método de ponderação de proporcionalidade pode ser fundamentado em normas constitucionais ou internacionais de direitos humanos, porque ambos os sistemas se dedicam à promoção e preservação dos mesmos valores essenciais.

No plano do direito internacional dos direitos humanos, essas ideias estão na base do chamado "processo de especificação dos sujeitos de direitos", segundo o qual, além de direitos gerais universais, extensíveis a todos, há necessidade de se reconhecer direitos específicos a determinados grupos dentro da sociedade. Isso com o objetivo de se atingir a igualdade real, ou pelo menos, reduzir as desigualdades de fato existentes agravadas em tempos de crise sanitária, como observado na pandemia do COVID-19.

\section{CONCLUSÃO}

A situação de excepcionalidade implementada pela pandemia de covid-19 desde o ano 2020 se constitui como a crise coletiva de saúde mais grave enfrentada nos últimos cem anos, sobretudo nos países ocidentais. Não custa lembrar que a chamada 'gripe espanhola' no início 
do século 20, no que diz respeito a sistemas jurídicos, ocorreu em período totalmente diverso do contemporâneo, quando não existia a ONU e nem mesmo a atual Declaração Universal de Direitos Humanos de 1948.

Isso significa que, naquela pandemia, os compromissos de cooperação dos estados e com os princípios fundamentais dos direitos humanos não possuíam a amplitude e o entrelaçamento atual.

O desenvolvimento do complexo das normas internacionais de direitos humanos durante o século 20, estendidas como obrigações inderrogáveis para os países membros da sociedade internacional, torna os ordenamentos internos vinculados, de modo que a eventual violação dos direitos fundamentais no ambiente interno dos países representa incidente ilícito perante os sistemas internacionais de direitos humanos.

Sucede que muitos países como o Brasil estão compelidos a aplicar medidas restritivas que afetam liberdades individuais, a exemplo da liberdade de reunião e da autonomia privada, privilegiando a promoção do Direito à Saúde, também qualificado como direito fundamental. Essa política incorre em violação de normas internacionais de direitos humanos, além de induzir tensão social interna relevante.

No entanto, soluções compatíveis podem ser encontradas também nas próprias convenções internacionais de direitos humanos, pela utilização de cláusulas de exceção, pela exortação de deveres fundamentais, ou pela promoção de soluções jurídicas de proporcionalidade entre normas internacionais de mesmo quilate.

O trabalho finaliza pela constatação de que o uso atual de cláusulas de exceção previstas em convenções de direitos humanos se justificam diante da amplitude da crise causada pela pandemia, os deveres fundamentais também funcionam como instrumentos disponíveis para situações de crise coletivas em auxílio à garantia dos direitos fundamentais, e o método de ponderação na validação concorrente de normas de direitos humanos internacionais pode oferecer alternativas de viabilidade de aplicação conjugada de direitos fundamentais.

\section{REFERÊNCIAS}

ALEXY, Robert. Teoria dos Direitos Fundamentais. São Paulo: Malheiros, 2008.

ALEXY, Robert. Colisão de Direitos Fundamentais e Realização de Direitos Fundamentais no Estado de Direito Democrático. Palestra na ESMAFE - Escola da Magistratura Federal em 07.12.1998, In Revista do Direito Administrativo, V. 217, FGV, 1999 <acesso em 30.03.2021> 
BARROS, Patrícia Ramos. A Problemática dos Deslocamentos Humanos em Tempos de Epidemia: restrição às migrações à luz dos Direitos Humanos, in Migrações, Deslocamentos, e Direitos Humanos. Org. George R B Galindo, p. 92-105. Brasília: IBDC. 2015.

BIDART CAMPOS, Germán J. Los 'Bienes Coletivos' en el Derecho Constitucional de los Derechos Humanos (Argentina), in Estudos de Direito Constitucional em homenagem a José Afonso da Silva, Coord, Eros Roberto Grau, Sérgio Sérvulo da Cunha, p.60-66. São Paulo: Malheiros, 2003.

BONAVIDES, Paulo. Curso de Direito Constitucional, 14.ed. São Paulo: Malheiros Editores, 2004.

BRASIL. Constituição de 1824. Disponível em: <http://www.planalto.gov.br>. Acesso em: 10/03/2021.

BRASIL. Constituição de 1891. Disponível em: <http://www.planalto.gov.br>. Acesso em: 10/03/2021.

BRASIL. Constituição de 1934. Disponível em: <http://www.planalto.gov.br>. Acesso em: 10/03/2021.

BRASIL. Constituição de 1946. Disponível em: <http://www.planalto.gov.br>. Acesso em: 10/03/2021.

BRASIL. Constituição de 1967. Disponível em: <http://www.planalto.gov.br>. Acesso em: 10/03/2021.

BRASIL. Constituição de 1969. Disponível em: <http://www.planalto.gov.br>. Acesso em: 10/03/2020.

BRASIL. Constituição de 1988. Disponível em: <http://www.planalto.gov.br>. Acesso em: 10/03/2021.

BURDEAU, Georges. O Estado. São Paulo: Martins Fontes, 2005.

COMPARATO, Fabio Konder. A Afirmação Histórica dos Direitos Humanos. São Paulo: Ed. Saraiva, 1999.

GARCIA, David Bondia. La exigibilidade del derecho a la salud em situaciones de crisis sanitárias. In El Derecho internacional de los derechos humanos em períodos de crisis: estudios desde la perspectiva de si aplicabilidade, p. 265-297. Eds. Jordi Bonet Perez/Jaume Saura Estapà. Madrid: Marcial Pons, 2013.

GUERRA FILHO, Willis Santiago. Sobre o Princípio da Proporcionalidade, in Dos Princípios Constituicionais: considerações em torno das normas principiológicas da constituição. Org. George Salomão Leite, p. 237-253. São Paulo: Malheiros, 2003.

GUERRA FILHO, Willis Santiago. Teoria Constitucional dos Princípios Jurídicos e Garantismo Penal: por uma atualização teórica de conceitos fundamentais, in Constituição e Democracia: estudos em homenagem ao Professor J J Gomes Canotilho. Coord. Paulo Bonavides, Francisco Gerson Marques de Lima, Fayga Silveira Bidê, p. 514-527. São Paulo: Malheiros, 2006.

LENZA, Pedro. Direito Constitucional esquematizado. 24 ed. São Paulo: Saraiva Educação, 2020

LIMA, Francisco Gerson Marques. Os Deveres Constitucionais: o cidadão responsável, in Constituição e Democracia: estudos em homenagem ao Professor J J Gomes Canotilho. Coord. Paulo Bonavides, Francisco Gerson Marques de Lima, Fayga Silveira Bidê, p. 140187. São Paulo: Malheiros, 2006.

MARTINS, Carlos Eduardo Behrmann Rátis. Introdução ao Estudo sobre os Deveres Fundamentais. Salvador: Editora Juspodium, 2011. 
PÉREZ, Jordi Bonet. Introducción General: Las Situaciones de Crisis y el Derecho Internacional de los Derechos Humanos. In El Derecho internacional de los derechos humanos em períodos de crisis: estudios desde la perspectiva de si aplicabilidade, p. 07-27. Eds. Jordi Bonet Perez/Jaume Saura Estapà. Madrid: Marcial Pons, 2013.

RAMOS, André de Carvalho. Curso de Direitos Humanos, 7. ed. São Paulo: Saraiva Educação, 2020.

SARMENTO, Daniel. Dignidade da Pessoa Humana:conteúdo, trajetórias e metodologia, 2. ed. Belo Horizonte: Editora Forum. 2016.

SIEYÈS, Emmanuel Joseph. A Constituinte Burguesa, 3. ed. Rio de Janeiro: Lumen Juris, 1997.

SILVA, De Plácido e. Vocabulário Jurídico, 16. ed. Rio de Janeiro: Forense, 1999.

SILVA, José Afonso da. Comentário Contextual à Constituição, 6. ed. São Paulo: Malheiros Editores, 2009.

SILVA, José Afonso da. Curso de Direito Constitucional Positivo, 16. ed. São Paulo: Malheiros Editores, 1999.

TORRES, Ricardo Lobo. A Cidadania Multidimensional na Era dos Direitos, in Teoria dos Direitos Fundamentais, 2. ed, p. 243-342. Org. Ricardo Lobo Torres. Rio de Janeiro: Renovar, 2001,

VENTURA, Deisy de Freitas Lima. DUARTE, Fabio Rijo. Atividades consideradas essenciais no Brasil durante a pandemia: discrepâncias entre as normas federais e estaduais, in Boletim $\mathrm{n}^{\mathrm{o}} 10$ - Direitos na Pandemia: mapeamento e análise das normas jurídicas de resposta à Covid-19 no Brasil. São Paulo: Conectas Direitos Humanos/CEPEDISA: FSP/USP, 2021. Acesso em: 03/04/2021.

VILLA, Marco Antonio. A História das Constituições Brasileiras. São Paulo: Leya, 2011. 